\title{
HSP70 (HSPA1) POLYMORPHISMS IN FORMER WORKERS WITH CHRONIC MERCURY VAPOR EXPOSURE
}

\author{
YURY I. CHERNYAK and ALLA P. MERINOVA \\ East-Siberian Institute of Medical and Ecological Research, Angarsk, Russia \\ Biochemical Group
}

\begin{abstract}
Objectives: To investigate 4 loci of 3 HSP70 genes in caustic soda production plant former workers, who have been exposed to metallic mercury vapors for a long time, and including numerous cases of chronic mercury intoxication (CMI). Material and Methods: Polymorphisms in HSP70 gene family members (HSP1A1 (+190G/C, rs1043618), HSPA1B (+1267A/G and $+2074 \mathrm{G} / \mathrm{C}$, rs1061581) and HSP1AL $(+2437 \mathrm{~T} / \mathrm{C}$, rs2227956)) genes were studied among 120 male workers involved in caustic soda production by mercury electrolysis at 2 plants in Eastern Siberia. These subjects had been chronically exposed to metallic mercury vapors for $>5$ years and divided into 3 groups based on the occurrence and time of the CMI diagnosis, or absence of this disease. The Group 1 consisted of individuals $(\mathrm{N}=46)$, who had had contact with mercury but were not diagnosed with the CMI. The Group 2 included workers $(\mathrm{N}=56)$, who were diagnosed with the CMI longer than 14 years ago. The Group 3 consisted of the subjects $(\mathrm{N}=18)$, who had been diagnosed with the CMI $3-5$ years ago. The logistic regression analysis was used for 3 genetic models with and without adjustment for age and duration of mercury vapor exposure. Results: We found that genotypes CC-HSPA1A $(+190 \mathrm{G} / \mathrm{C})$ and GG-HSPA1B $(+1267 \mathrm{~A} / \mathrm{G})$ had a high predictive risk of the CMI development (adjusted odds ratio $\left(\mathrm{OR}_{\text {adj }}\right)=5.58, \mathrm{p}=0.026$ and $\mathrm{OR}_{\mathrm{adj}}=14.7, \mathrm{p}=0.0015$, respectively). Twelve individuals with the CMI had a specific combination of CC-HSPA1A $(+190 \mathrm{G} / \mathrm{C})$ and GG-HSPA1B $(+1267 \mathrm{~A} / \mathrm{G})$ genotypes, which strongly associated with the diagnosis $\left(\mathrm{OR}_{\text {adj }}=12.3, \mathrm{p}=0.0285\right)$. Moreover, significant association with the CMI was also obtained for the haplotype G-C of $1267 \mathrm{~A} / \mathrm{G}$ and $190 \mathrm{G} / \mathrm{C}$ polymorphisms (OR $=2.1, \mathrm{p}=0.018)$. Conclusions: The association of CC-HSPA1A $(+190 \mathrm{G} / \mathrm{C})$ and GG-HSPA1B $(+1267 \mathrm{~A} / \mathrm{G})$ genotypes and their combination for the CMI individuals suggests the role for HSPA1 genes in mercury-dependent mechanisms of the CMI development and progression. Int J Occup Med Environ Health 2017;30(1):77-85
\end{abstract}

\section{Key words:}

Chronic mercury vapor exposure, Chronic mercury intoxication, Heat shock protein 70, HSPA1 polymorphisms, Genetics in occupational health, Association with chronic mercury intoxication

\section{INTRODUCTION}

The exposure to toxic levels of metallic mercury vapor $\left(\mathrm{Hg}^{0}\right)$ for humans is accompanied by undesirable effects on many systems and organs, including the central nervous system. The primary route of $\mathrm{Hg}^{0}$ exposure is by inhalation from occupational sources. Absorbed through the lungs, lipophilic $\mathrm{Hg}^{0}$ dissolves in blood, easily passes the blood-brain barrier and reacts with organic compounds leading to its accumulation in the brain [1]. Metallic mercury vapor intoxication is accompanied by a wide range of cognitive, personality, sensory and motor disorders [1-5].

Funding: the work was supported in part by the Program of Basic Research of the Russian Academy of Sciences "Basic Sciences for Medicine" (project No. 29). Project manager: Yury I. Chernyak, Ph.D., D.Sc.

Received: July 6, 2015. Accepted: January 4, 2016.

Corresponding author: Y.I. Chernyak, East-Siberian Institute of Medical and Ecological Research, Biochemical Group, P.O. Box 1170, Angarsk 665827, Russia (e-mail: yuri_chernyak@hotmail.com). 
The pathophysiological mechanisms of the development and progression of the severe organic brain damage for individuals with long term chronic mercury intoxication (CMI) remain to be poorly investigated [6]. Nuclear magnetic resonance (NMR) imaging has revealed that $\mathrm{CMI}$ individuals have lesions consistent with subatrophy of the cerebellum. This morphological change is considered as an indication of neurodegenerative processes.

Stress proteins, particularly the heat shock proteins (HSPs), have a major cytoprotective role in neurodevelopmental diseases and therefore their aberrant function may mediate the adverse effects of CMI [7,8]. Heat shock protein 70 (HSP70 (HSPA)) cooperates with several other chaperone proteins during folding of damaged or newly synthesized proteins and provides conformational regulation upon signaling proteins, thus playing a role as a key component during maintenance of cellular homeostasis $[9,10]$. Upon absorption into the body, mercury causes an increase in the synthesis and cellular concentration of HSP70 in blood and target organs [11] and the presence of mercury in the brain is accompanied by the accumulation of aberrant and misfolded proteins [12]. Exposed to metallic mercury vapors individuals frequently develop neurodegenerative diseases and there is limited data examining the pathogenesis of this process. For example, a rare case of Parkinson's syndrome development for a 50-year-old patient who had been occupationally exposed to metallic mercury vapors for 33 years in chlorine chemical production plant was reported by Miller et al. [13]. Exposure to $\mathrm{Hg}^{0}$ by this individual was confirmed by the detection of $18.3 \mu \mathrm{g} / \mathrm{g}$ creatinine of mercury in urine.

Based on these reports, we hypothesized that the polymorphisms in HSP70 genes could differentially affect sensitivity to mercury in a similar to other stressors fashion. Several studies support this hypothesis. For example, significant decrease in heat shock-dependent induction of HSP70 was reported in mononuclear cells of young carriers of the HSPA1L-CC genotype in comparison with genotypes TC and TT at HSPA1L gene locus 2437T/C [14]. These findings suggested that this particular polymorphism may affect the chaperoning function of HSP70, whereas the $\mathrm{CC}$ genotype was unfavorable for human longevity. In another study, the A allele of $\operatorname{HSPA1B}(1267 \mathrm{~A} / \mathrm{G})$ was not associated with an increase in messenger ribonucleic acid (mRNA) levels [15]. It was assumed that this allele is linked to the $\mathrm{C}$ dominant allele of $H S P A 1 B$ $(-179 \mathrm{C} / \mathrm{T})$ and the CC genotype, which were associated with lower HSPA1A and HSPA1B mRNA levels and affected HSP70 production. Furthermore, HSP70 amount in human serum decreased with age in the normal population and inflammatory pathologies in elderly individuals were associated with elevated HSP70 levels [16].

However, it is currently unknown whether there is an association of polymorphisms in HSPs genes with the mechanisms which are important for the development and progression of the CMI. Such information would provide valuable insight into the pathogenesis of this disease and also help to develop the criteria for assessing individual's susceptibility and its risk to developing the CMI. The present study was designed to investigate the relationship between polymorphic variants of HSP70 genes and the CMI in caustic soda production plant former workers, who were chronically exposed to $\mathrm{Hg}^{0}$ and frequently developed the CMI.

\section{MATERIAL AND METHODS}

\section{Subjects}

The current study examined 120 male workers who had been involved in the production of caustic soda by mercury electrolysis and therefore were chronically exposed to metallic mercury vapors for $>5$ years. These subjects were subdivided into 3 groups, which were formed based on the results of regular medical examinations. The Group 1 included 46 individuals (average age 49.9 \pm 5.3 years old and average duration of mercury vapor exposure $21.4 \pm 6.5$ years) who had not been diagnosed with the CMI. The Group 2 included 56 individuals $(53.3 \pm 6$ years old and $15.5 \pm 5.8$ years) 
who were diagnosed with the CMI more than 14 years ago. The Group 3 included 18 individuals ( $47.8 \pm 7.8$ years old and $19.3 \pm 7.5$ years) who were diagnosed with the CMI within the last 3-5 years.

All workers were from 2 plants located in Sayansk and Usolye-Sibirskoye cities of Irkutsk region (Eastern Siberia, Russia). The first plant (groups 1 and 3) utilized mercury electrolysis technology from 1979 to 2006, while the second plant (group 2) applied it from 1943 to 1998. Mercury electrolysis technologies were ended after these times and both companies now use diaphragm technology for caustic soda production eliminating mercury exposure. Venous blood samples were collected in the Clinical Department of the East Siberian Scientific Center of Human Ecology in Angarsk, Russia during the period of 2005-2011. Informed consent was provided by all participants. The study protocol was approved by the Biomedical Ethics Committee of the East-Siberian Scientific Center of Siberian Branch of the Russian Academy of Medical Sciences in Irkutsk, Russia. All samples were stored at $-70^{\circ} \mathrm{C}$ before the analysis.

\section{Exposure}

Air pollution by mercury vapors in the working area in Sayansk plant and mercury presence in blood samples of plant workers were measured from 1987 to 2005 [17]. The highest annual average concentrations of metallic mercury vapors $\left(0.08-0.2 \mathrm{mg} / \mathrm{m}^{3}\right)$ were found at the mercury electrolysis plant during 1987-1992. In subsequent years, the annual average concentrations decreased to $0.015-0.037 \mathrm{mg} / \mathrm{m}^{3}$ and remained within that range until the introduction of the new technology. At the time of examination, workers from the mercury sludge regeneration department had the highest average mercury blood concentration $(74.93 \pm 8.97 \mu \mathrm{g} / \mathrm{l})$ and their urine mercury levels ranged 6-78 $\mu \mathrm{g} / \mathrm{l}$.

The annual average concentration of mercury vapor in Usolye-Sibirskoye plant during 1990-1998 varied from $0.013 \mathrm{mg} / \mathrm{m}^{3}$ to $0.071 \mathrm{mg} / \mathrm{m}^{3}$, with the maximum concentrations $0.072-0.17 \mathrm{mg} / \mathrm{m}^{3}$ [18]. Sharp increase in the maximum concentration $\left(0.16-0.77 \mathrm{mg} / \mathrm{m}^{3}\right)$ was observed after the start of the dismantling of industrial machinery and equipment for mercury electrolysis in 20002003, whilst average concentrations remained unchanged. In 2005-2006, shortly before Sayansk plant was converted to the new diaphragm technology, urinary mercury levels $(\mu \mathrm{g} / 1)$ in workers from groups $1-3$ were (n/mean (min.$\max )$ ): 49/6.22 $\mu \mathrm{g} / 1(0-55 \mu \mathrm{g} / \mathrm{l}), 35 / 0.21 \mu \mathrm{g} / \mathrm{l}(0-2 \mu \mathrm{g} / \mathrm{l})$, and 9/18.22 $\mu \mathrm{g} / \mathrm{l}(4-38 \mu \mathrm{g} / \mathrm{l})$, respectively.

\section{Results of clinical examinations}

The long-term monitoring (from the 1970's) of the workers from both plants and clinical examination of the recruited subjects (in 2005-2011) was performed by certified clinical specialists in the fields of neurology and occupational diseases from the Clinic of the East Siberian Scientific Center of Human Ecology in Angarsk, Russia.

Nervous system damage in individuals with the diagnosed occupational CMI was characterized by the severity of the clinical manifestations of intoxication and its progression, and by the formation of organic lesions in the nervous system. In the early stages of observation, the clinical pathology of the nervous system appeared as an asthenic (emotionally labile) disorder, accompanied by the autonomic dysfunction, cardiovascular disorders and cephalalgia (chronic tension-type headache) [6] .

Overall, the content of mercury in blood and urine was often higher than background regional levels, reaching $20 \mu \mathrm{g} / \mathrm{l}$ and $5 \mu \mathrm{g} / \mathrm{l}$, respectively. The asthenic syndrome was presented with common complaints and often accompanied by emotional violations such as mild depression and hypochondriasis. Individuals from groups 2 and 3 were diagnosed with the occupational CMI resulting from longterm chronic mercury exposure. At this stage of disease development, $100 \%$ of individuals with the CMI were diagnosed with toxic encephalopathy, which included the following clinical syndromes: organic personality disorders $(80 \%)$, organic emotionally labile disorder (16.4\%), 
overlay or progression of the severity of cognitive disorder $(92.7 \%)$, shaking hyperkinesis (manifested in the early stages only as hand tremors mediated outside the central nervous system that subsequently spread to the legs and head (23.6\%)) and others [19].

The current study was conducted in 2 stages. After 2-3 years (the second stage of examination), samples from individuals not involved in the earlier study were combined with the samples collected during the first stage [20]. During the time between examinations, some individuals from group 1 were diagnosed with the CMI and the stage of disease for some individuals in groups 2 and 3 changed (stage 2 of $14.3 \%$ of the CMI individuals changed to stage 3) [19]. These changes were taken into account when analyzing the data.

\section{Analysis of $H S P 70$ gene polymorphisms}

The best studied gene polymorphisms of HSP70 (HSPA1) family - HSPA1B (+2074G/C and +1267A/G, rs1061581), HSPA1A (+190G/C, rs1043618) and HSPA1L (+2437T/C, rs2227956) - were selected for analysis. The HSPA1A and HSPA1B are the most stress-inducible proteins, whereas HSPA1L is constitutively synthesized [21,22].

Venous blood samples were collected from individuals by standard procedures into $4 \mathrm{ml}$ vacutainer tubes with tri-potassium salt of ethylenediaminetetraacetic acid (K $\mathrm{K}_{3}$-EDTA). Deoxyribonucleic acid (DNA) was extracted using the "DNA-sorb-B" kit (AmpliSens, Russia).

For polymorphic analysis, polymerase chain reaction (PCR) was carried out in a Tertsik amplifier (DNATechnology, Russia) and restriction fragment length polymorphisms were analyzed. Primers, PCR conditions, and restriction endonucleases used for genotyping were according to a paper of $\mathrm{Li}$ et al. [10]. The primers synthesized by Medigen Company (Russia) and restriction endonucleases from Fermentas/Thermo Scientific (Lithuania) were used for genotyping. Amplification mixture $(25 \mu \mathrm{l})$ contained $10 \mathrm{pM}$ each primer, $2.5 \mu \mathrm{l} 10 \times$ buf- fer (Sigma-Aldrich, USA), 1.5-2.5 mM magnesium chloride $\left(\mathrm{MgCl}_{2}\right)$ (Sigma-Aldrich, USA), $0.2 \mathrm{mM}$ each deoxynucleotide (dNTP), and $1 \mathrm{U}$ Taq-polymerase. The electrophoresis for $H S P A 1 B$ and $H S P A 1 L$ genes was performed in $1.5 \%$ agarose gel and for $H S P A 1 A$ gene - in $7.5 \%$ polyacrylamide gel, followed by ethidium bromide staining and transmitted UV light analysis.

\section{Statistical analysis}

The statistical data analysis was performed using Statistica software package version 6.1 (StatSoft Inc., USA). Because the groups 2 and 3 of individuals with the CMI diagnosis included a small number of subjects, they were combined for analysis. Two versions of the logistic regression analysis were used for each genetic model (dominant, recessive and additive), with and without adjustment for age and duration of mercury vapor exposure as conventional risk factors. The Akaike information criteria (AIC) were used for choosing the model that best fits the data. This analysis and tests for association between haplotypes and the CMI development was done using open-source SNPStats software [23]. The results were expressed as odds ratio (OR), 95\% confidence interval (CI) and $p$-value. The confidence level of $p<0.05$ was used as the criteria for statistical significance. The $\mathrm{Chi}^{2}$ test was used to check for deviation from Hardy-Weinberg equilibrium [24].

\section{RESULTS}

The genotype frequency distribution for all studied polymorphisms in groups corresponded with Hardy-Weinberg equilibrium. The results of 2 type logistic regression analysis for each genetic model (with and without adjustment for age and duration of mercury vapor exposure as independent variables) are summarized in the Table 1. The data of genotypes distribution was used from 2 groups - with and without the CMI diagnosis (the combined group (groups 2 and 3) and group 1, respectively). 


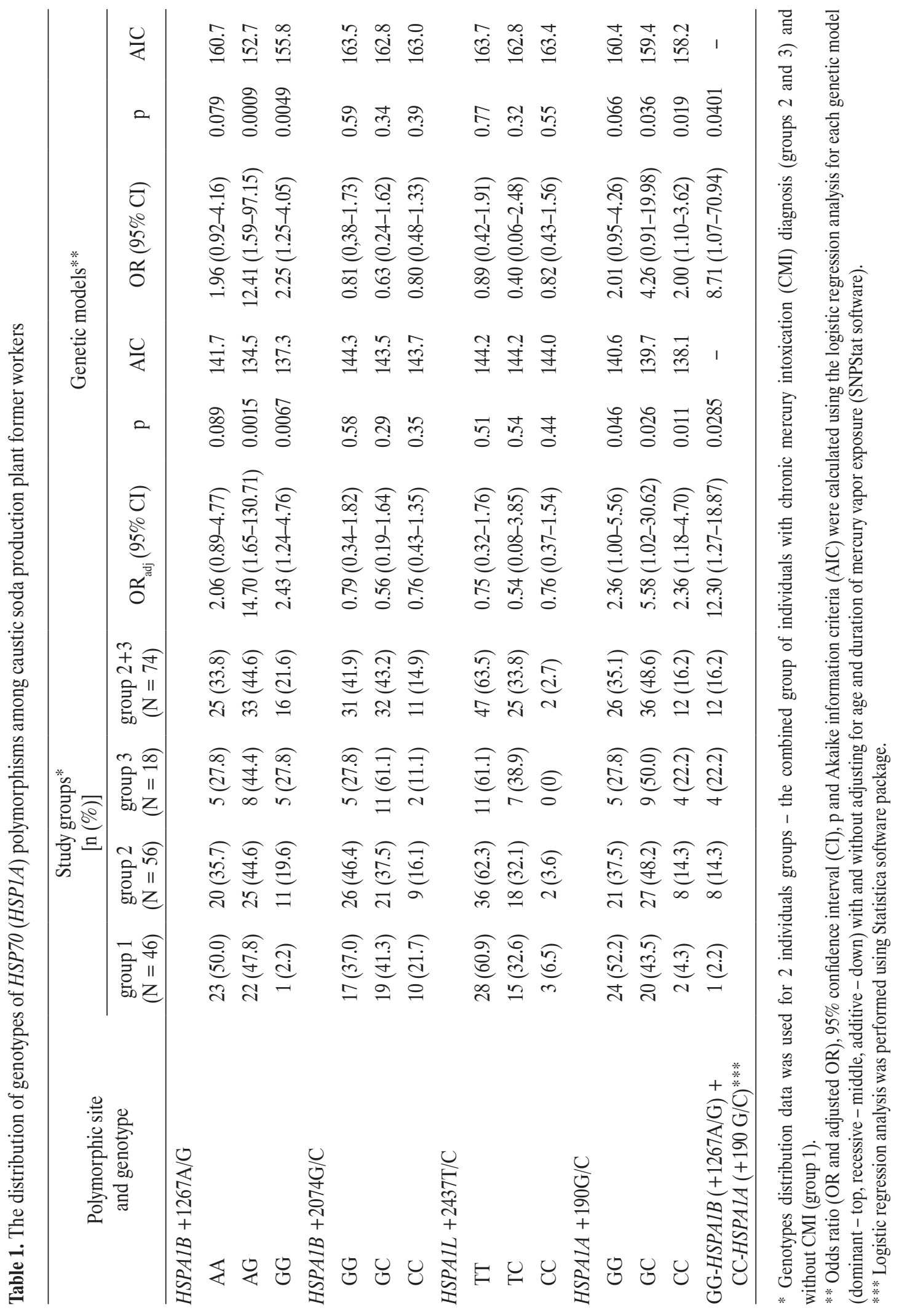


Table 2. Haplotype frequencies of the 2 studied polymorphisms among caustic soda production plant former workers $(\mathrm{N}=120)^{*}$

\begin{tabular}{cccccc}
\hline Haplotype & $H S P A 1 B(+1267 \mathrm{~A} / \mathrm{G})$ allele & $\operatorname{HSPA1A}(+190 \mathrm{G} / \mathrm{C})$ allele & Frequency & OR $(95 \% \mathrm{CI})$ & $\mathrm{p}$ \\
\hline 1 & $\mathrm{~A}$ & $\mathrm{G}$ & 0.6163 & 1.00 & - \\
2 & $\mathrm{G}$ & $\mathrm{C}$ & 0.3371 & $2.10(1.14-3.87)$ & 0.018 \\
3 & $\mathrm{G}$ & $\mathrm{G}$ & 0.0337 & $5.61(0.65-48.35)$ & 0.120 \\
4 & $\mathrm{~A}$ & $\mathrm{C}$ & 0.0129 & $1.76(0.15-20.90)$ & 0.650 \\
\hline
\end{tabular}

* All indexes were calculated using SNPStat software.

$\mathrm{OR}$ - odds ratio; $\mathrm{CI}$ - confidence interval.

Significant genetic associations were found for the loci HSPA1B (+1267A/G) and HSPA1A (+190G/C). A higher frequency of genotype GG-HSPA1B $(+1267 \mathrm{~A} / \mathrm{G})$ was detected in the combined group of individuals with the CMI diagnosis (groups 2 and 3). The $+1267 \mathrm{G}$ allele was highly associated with CMI development under both recessive and additive genetic models (adjusted odds ratio $\left(\mathrm{OR}_{\text {adj }}\right)=14.7, \mathrm{p}=0.0015$ and $\mathrm{OR}=12.41, \mathrm{p}=0.0009$, $\mathrm{OR}_{\text {adj }}=2.43, \mathrm{p}=0.0067$ and $\mathrm{OR}=2.25, \mathrm{p}=0.0049$, respectively).

In the HSPA1A $(+190 \mathrm{G} / \mathrm{C})$ locus, the $+190 \mathrm{C}$ allele was associated with the CMI development under the adjusted version of recessive model and in both additive models $\left(\mathrm{OR}_{\mathrm{adj}}=5.58, \mathrm{p}=0.026, \mathrm{OR}_{\mathrm{adj}}=2.36, \mathrm{p}=0.011\right.$ and $\mathrm{OR}=2, \mathrm{p}=0.019$, respectively). There were no significant associations found for the loci HSPA1B $(+2074 \mathrm{G} / \mathrm{C})$ and HSPA1L (+2437T/C). The models with less Akaike information value that best fits the data were recessive for the $+1267 \mathrm{G}$ allele $\left(\mathrm{AIC}_{\text {adj }}=134.5, \mathrm{AIC}=152.7\right)$ and the additive for the $+190 \mathrm{C}$ allele $\left(\mathrm{AIC}_{\mathrm{adj}}=138.1, \mathrm{AIC}=158.2\right)$. In the case of $H S P A 1 B(+1267 \mathrm{~A} / \mathrm{G})$ locus for recessive model after adjustment for age and mercury time exposure increase of odds ratio from OR $=12.41(\mathrm{p}=0.0009)$ to $\mathrm{OR}_{\text {adj }}=14.7(\mathrm{p}=0.0015)$ was noticed. For additive models of loci HSPA1B $(+1267 \mathrm{~A} / \mathrm{G})$ and HSPA1A (+190G/C) the change was non-significant (slight increase) from $\mathrm{OR}=2.25(\mathrm{p}=0.0049)$ to $\mathrm{OR}_{\text {adj }}=2.43(\mathrm{p}=0.0067)$ and $\mathrm{OR}=2(\mathrm{p}=0.019)$ to $\mathrm{OR}_{\mathrm{adj}}=2.36(\mathrm{p}=0.011)$, respectively. Significant models adjusted for age and duration of mercury vapor exposure fit better (based on OR level) compared to the models based only on genotypes of polymorphic variants of genes.

The analysis of differences in the distribution of genotypes amongst the individuals revealed that the $\mathrm{CC}$ HSPA1A $(+190 \mathrm{G} / \mathrm{C})$ genotype was frequently accompanied by the GG-HSPA1B $(+1267 \mathrm{~A} / \mathrm{G})$ genotype, except for 1 case in the group 1 . This was detected for 12 people from 74 individuals (16.2\%) diagnosed with the CMI (groups 2 and 3). Moreover, 12 carriers of this specific genotype combination from 13 cases $(92.3 \%)$ had the CMI. Logistic regression showed that this genotype combination was significantly associated with the CMI development. After adjusting for age and time of exposure, we found the increase in OR for carriers of GG-HSPA1B $(+1267 \mathrm{~A} / \mathrm{G})$ and CC-HSPA1A (+190G/C) genotype combinations from $8.71(\mathrm{p}=0.0401)$ to $12.3(\mathrm{p}=0.0285)$.

Haplotype analysis was also performed for 4 possible allele combinations for the loci HSPA1B $(+1267 \mathrm{~A} / \mathrm{G})$ and HSPA1A (+190G/C) (Table 2). Only haplotype G-C had a significant 2.1-fold increased odds ratio for the CMI development $(\mathrm{OR}=2.1,95 \% \mathrm{CI}: 1.14-3.87, \mathrm{p}=0.018)$.

\section{DISCUSSION}

Chronic exposure to toxic levels of $\mathrm{Hg}^{0}$ has dramatic effects on human body, especially the central nervous system. Polymorphisms in HSP70 genes could differentially affect sensitivity to mercury, but it is unknown whether there is an association of polymorphisms in HSPs genes with 
the development and progression of the CMI in workers chronically exposed to $\mathrm{Hg}^{0}$. Our study provides the first evidence that carriers of genotypes CC-HSPA1A (+190G/C) and GG-HSPA1B $(+1267 \mathrm{~A} / \mathrm{G})$, or their combination, have high predictive risk of the CMI development.

In particular, we found the $\mathrm{OR}_{\mathrm{adj}}=5.58(\mathrm{p}=0.026)$ for carriers of $\mathrm{CC}$ minor homozygote for the locus HSPA1A $(+190 \mathrm{G} / \mathrm{C})$ and almost 4-fold statistically significant higher frequency of that genotype in individuals with the CMI diagnoses in combined group (groups 2 and 3) (16.2\%) compared with the individuals from the group 1 without that diagnosis (4.3\%). These findings are in accordance with the data by Wu et al. [25], who reported a significant higher frequency of genotypes $-110 \mathrm{CC}$ and $190 \mathrm{CC}$ at HSPA1A in individuals with Parkinson's syndrome vs. control group and suggested their association with neurodegenerative diseases.

Moreover, in our study, the high ORs $\left(\mathrm{OR}_{\mathrm{adj}}=14.7\right.$, $\mathrm{p}=0.0015$ and $\mathrm{OR}=12.41, \mathrm{p}=0.0009)$ for GG-HSPA1B $(+1267 \mathrm{~A} / \mathrm{G})$ genotype between the combined group (groups 2 and 3) of individuals with the CMI where found, when compared with the group of workers without the disease. The possibility that individuals homozygous for the rare $\mathrm{G}$ allele of $H S P A 1 B(+1267 \mathrm{~A} / \mathrm{G})$ may associate with increased expression $H S P A 1 A$ and $H S P A 1 B$ has not been excluded by others [15]. Together with these findings, observed by us higher GG genotype frequency in the combined CMI group suggests an association between increases in HSPs mRNA levels and the development of neurodegenerative diseases.

In this study, the combination of CC-HSP1A1 (+190G/C) and GG-HSPA1B $(+1267 \mathrm{~A} / \mathrm{G})$ genotypes in several individuals with the CMI development was detected. It was also found for 1 patient in the group 1 (age 33 years and duration of mercury vapor exposure 13 years). These results emphasize the need to monitor this individual further, because of his young age and potential risk of developing the CMI in the future.
Of particular interest is the 1.4-fold increase of OR value after adjusting for age and years of mercury exposure for carriers of named genotype combinations. This finding indicates the importance of including these 2 factors, which modify association levels of genotype combinations with the CMI development and increase model significance, into the analysis. The haplotype examination confirmed the presence of synergistic effect between the loci HSPA1B $(+1267 \mathrm{~A} / \mathrm{G})$ and HSPA1A (+190G/C). This included the detection of a significant association for haplotype G-C (both rare alleles) with the CMI development $(\mathrm{OR}=2.1, \mathrm{p}=0.018)$. These findings indirectly prove genetic interaction and complements genetic model results. Despite the significance of our findings for the field of occupational diseases, the present study has a number of limitations which should be taken into account. First of all, it included a relatively small number of subjects. Nevertheless, the distinctions in HSP genotypes distribution detected with a limited sample were assessed relative to another group of individuals (group 1) chronically exposed to mercury vapor and not diagnosed with the CMI at the time of examination. It is possible that some individuals from this group will develop the CMI in the future.

Study of the control group of individuals without occupational mercury exposure may allow understanding of the proportion of carriers within the population of minor homozygotes and their combinations, which are highly associated with the CMI development, as our study demonstrated. Secondly, only 4 polymorphisms of HSP70 genes were analyzed here, with additional modifying factors limited to age and duration of mercury vapor exposure, as independent variables. Total mercury burden would be the most likely causative factor rather than any secondary risk factor (e.g., time of exposure, etc.), but unfortunately the data about the latter were not available.

Altogether, these points highlight the significance and the perspectives of our findings for the design of future 
research studies using a cohort of the CMI individuals from a different population (i.e., the need for a replication study), backgrounds and, importantly, exposures to other conventional risk factors.

In summary, our study demonstrated strong genetic associations for 2 genotypes of HSP1A genes, as well as their combination, with the CMI development. Whether HSP70 levels are affected in caustic soda production plant workers, who have been chronically exposed to metallic mercury vapors and with many cases of the CMI development, remains to be investigated in the future studies.

\section{CONCLUSIONS}

Our study revealed homozygotes for the rare alleles of loci HSPA1A (+190G/C) and HSPA1B $(+1267 \mathrm{~A} / \mathrm{G})$ as novel and strong predictors of the risk of the CMI development. We found that individuals with the CMI have a specific combination of CC-HSPA1A (+190G/C) and GGHSPA1B $(+1267 \mathrm{~A} / \mathrm{G})$ genotypes, whilst individuals from all groups had chronic exposure to metallic mercury vapor. Because higher frequencies of these genotypes is associated with several neurodegenerative diseases, our findings in individuals with the CMI suggest a role for polymorphic variants of $H S P A 1$ genes in pathogenesis of this disease. Future studies examining HSPA1 genotypes in individuals not occupationally exposed to mercury would provide further insights.

Besides suggesting this avenue for dissecting mechanisms of chronic mercury intoxication in neurodegenerative processes, our findings contribute to the development of assessment criteria for an individual's susceptibility to mercury exposure and the risk of developing the CMI.

\section{ACKNOWLEDGMENTS}

The authors thank Dr. Leonid L. Nikitenko (University of Oxford, UK) for assistance with translation, helpful discussions and comments.

\section{REFERENCES}

1. World Health Organization. Concise international chemical assessment document 50. Elemental mercury and inorganic mercury compounds: Human health aspects. Geneva: The Organization; 2003.

2. Ellingsen DG, Bast-Pettersen R, Efskind J, Thomassen Y. Neuropsychological effects of low mercury vapor exposure in chloralkali workers. Neurotoxicology. 2001;22:249-58, https://doi.org/10.1016/S0161-813X(01)00012-2.

3. Bast-Pettersen R, Ellingsen DG, Efskind J, Jordskogen R, Thomassen Y. A neurobehavioral study of chloralkali workers after the cessation of exposure to mercury vapor. Neurotoxicology. 2005;26:427-37, https://doi.org/10.1016/ j.neuro.2005.03.006.

4. Tang N, Li YM. Neurotoxic effects in workers of the clinical thermometer manufacture plant. Int J Occup Med Environ Health. 2006;19:198-202, https://doi.org/10.2478/v10001006-0023-8.

5. Wastensson G, Lamoureux D, Sällsten G, Beuter A, Barregård L. Quantitative assessment of neuromotor function in workers with current low exposure to mercury vapor. Neurotoxicology. 2008;29:596-604, https://doi.org/10.1016/ j.neuro.2008.03.005.

6. Lakhman OL, Katamanova EV, Konstantinova TN, Shevchenko OI, Meshcheryagin VA, Andreeva OK, et al. [Contemporary approaches to the classification of occupational mercury intoxication]. Hum Ecol. 2009;12:22-7. Russian.

7. Turturici G, Sconzo G, Geraci F. Hsp70 and its molecular role in nervous system diseases. Biochem Res Int. 2011;2011: 18, https://doi.org/10.1155/2011/618127.

8. Mansilla MJ, Montalban X, Espejo C. Heat shock protein 70: Roles in multiple sclerosis. Mol Med. 2012;18:1018-28, https://doi.org/10.2119/molmed.2012.00119.

9. Young JC, Moarefi I, Hartl FU. Hsp90: A specialized but essential protein-folding tool. J Cell Biol. 2001;154:267-73, https://doi.org/10.1083/jcb.200104079.

10. Li JX, Tang BP, Sun HP, Feng M, Cheng ZH, Niu WQ. Interacting contribution of the 5 polymorphisms in 3 genes 
of Hsp70 family to essential hypertension in Uygur ethnicity. Cell Stress Chaperones. 2009;14:355-62, https://doi. org/10.1007/s12192-008-0089-2.

11. Goering PL, Fisher BR, Noren BT, Papaconstantinou A, Rojko JL, Marler RJ. Mercury induces regional and cellspecific stress protein expression in rat kidney. Toxicol Sci. 2000;53:447-57, https://doi.org/10.1093/toxsci/53.2.447.

12. Cavanagh JB. Long term persistence of mercury in the brain. Br J Ind Med. 1988;45:649-51, https://doi.org/10.1136/ oem.45.10.649.

13. Miller K, Ochudło S, Opala G, Smolicha W, Siuda J. [Parkinsonism in chronic occupational metallic mercury intoxication]. Neurol Neurochir Pol. 2003;37(Suppl 5):31-8. Polish.

14. Singh R, Kølvraa S, Bross P, Jensen UB, Gregersen N, Tan Q, et al. Reduced heat shock response in human mononuclear cells during aging and its association with polymorphisms in HSP70 genes. Cell Stress Chaperones. 2006;11:208-15, https://doi.org/10.1379/CSC-184R.1.

15. Temple SE, Cheong KY, Ardlie KG, Sayer D, Waterer GW. The septic shock associated HSPA1B1267 polymorphism influences production of HSPA1A and HSPA1B. Intensive Care Med. 2004;30:1761-7, https://doi.org/10.1007/s00134004-2359-5.

16. Njemini R, Bautmans I, Onyema OO, Puyvelde KV, Demanet C, Mets T. Circulating heat shock protein 70 in health, aging and disease. BMC Immunol. 2011;12:24, https://doi. org/10.1186/1471-2172-12-24.

17. Shayakhmetov SF, Lisetskaya LG, Meshakova NM. [Assessment of air pollution with mercury in working zone and its content in biomaterials of employees at the caustic and chlorine production]. Bull VSNC SO RAMN. 2010;74:59-63. Russian.
18. Bezgodov IV, Laptev IF, Rogaleva VV, Efimova NV, Andreeva OK. [Mercury danger assessment at the enterprises of chemical industry in Irkutsk region]. Bull VSNC SO RAMN. 2005;40:70-4. Russian.

19. Rukavishnikov VS, Lakhman OL, Sosedova LM, Shaiakhmetov SF, Bodienkova GM, Kudaeva IV, et al. [Occupational neurointoxications: Patterns and mechanisms of formation]. Med Tr Prom Ekol. 2014;(4):1-6. Russian.

20. Chernyak YI, Itskovich VB, Baduev BK, Borovskii G. Dependence of blood levels of HSP70 and HSP90 on genotypes of HSP70, GSTT1, and GSTM1 gene polymorphism in individuals chronically exposed to mercury. Bull Exp Biol Med. 2012;154:68-72, https://doi.org/10.1007/s10517-012-1877-3.

21. Vos MJ, Hageman J, Carra S, Kampinga HH. Structural and functional diversities between members of the human HSPB, HSPH, HSPA, and DNAJ chaperone families. Biochemistry. 2008;47:7001-11, https://doi.org/10.1021/bi800639z.

22. Kampinga HH, Hageman J, Vos MJ, Kubota H, Tanquay RM, Bruford EA, et al. Guidelines for the nomenclature of the human heat shock proteins. Cell Stress Chaperones. 2009;14:105-11, https://doi.org/10.1007/s12192-008-0068-7.

23. Solé X, Guinó E, Valls J, Iniesta R, Moreno V. SNPStats: A web tool for the analysis of association studies. Bioinformatics. 2006;22:1928-9, https://doi.org/10.1093/bioinformatics/bt1268.

24. Rodriguez S, Gaunt TR, Day IN. Hardy-Weinberg equilibrium testing of biological ascertainment for Mendelian randomization studies. Am J Epidemiol. 2009;169:505-14, https://doi.org/10.1093/aje/kwn359.

25. Wu YR, Wang CK, Chen CM, Hsu Y, Lin SJ, Lin YY, et al. Analysis of heat-shock protein 70 gene polymorphisms and the risk of Parkinson's disease. Hum Genet. 2004;114: 236-41, https://doi.org/10.1007/s00439-003-1050-1.

This work is available in Open Access model and licensed under a Creative Commons Attribution-NonCommercial 3.0 Poland License - http://creativecommons.org/ licenses/by-nc/3.0/p1/deed.en. 